\title{
Stature estimation from digit length, bi-acromian and bi-illiac length: a study among two populations from eastern and north eastern India
}

\begin{abstract}
Background: Identification of human remains in medico-legal situation contribution of forensic anthropology is imperative. Forensic anthropology deals with identification of age, sex and ethnicity. Apart from that estimation of stature is found to be one of the major parameters of forensic anthropology, is an essential element of medico-legal investigations when identifications of unknown dismembered remains are involved. The publication regarding estimation of statute seems to be scanty from Eastern India and specially from North East India.
\end{abstract}

Aim: The present study was conducted with an aim to estimate stature from 2D, 4D, Bi-acromian length and Bi-illiac length of adult age matched females belonging to Bengalee Hindu Caste Population from Eastern India and one of the ethnic groups (Chakmas) of North East India (Tripura).

Materials and methods: To achieve the purpose, the participants of the present study were comprised of 100 Chakma females and 100 Bengalee females of 25 to 35 years age ranges. Prior to the study verbal consent were obtained from the participants. The ring finger is the fourth digit (4D) of the human hand and the second most ulnar finger located between the middle finger and the little finger while the index finger is the second digit (2D), located between the thumb and the middle finger and usually the most dexterous and sensitive finger of the hand were measured using standard method. Along with digit measurements, stature was obtained using standard technique. Obtained data were doubly checked and analyzed using the SPSS (Version- 16.0). Descriptive and inferential statistics were done in appropriate places and cut off was set as $\mathrm{p}=0.05$.

Results: Distributions of the anthropometric variables including 2D and 4D demonstrated significant $(\mathrm{p}<0.05)$ between the age matched Bengalee and the Chakma females for all the characteristics. Examination of estimation of stature using multiplication factors revealed least mean value for the bi-illiac length while, the highest being the mean value for $2 \mathrm{D}$ among both the population. However, the comparison between the population the mean multiplication factors for estimation of stature, the length of $2 \mathrm{D}, 4 \mathrm{D}$ and Bi-illac length demonstrated significant $(\mathrm{p}<0.05)$ difference between the two population groups. So far the forensic issues concern regarding the stature estimation by multiplication factors, the best predictors were Bi-illica length followed by Bi-acromian length for both the studied populations. The correlation analysis demonstrated most of the measurements demonstrated significant $(\mathrm{p}<0.05)$ positive correlation with stature except bi-acromian and bi-illiac among the Bengalee females and Chakma females respectively.

Conclusion: The study concludes that stature estimation from $2 \mathrm{D}$ and $4 \mathrm{D}$ lengths along with bi-acromian and bi-illiac lengths could be utilized for specific population group.
Volume 6 Issue 6 - 2018

\section{Kusum Ghosh, Priyama Bhattacharya, Sumit Maitra, Diptendu Chatterjee, Arup Ratan Bandyopadhyay}

Department of Anthropology, University of Calcutta, 35 Ballygunge circular Road, Kolkata - 700019, India

Correspondence: Arup Ratan Bandyopadhyay, Department of Anthropology, University of Calcutta, 35, Ballygunge circular Road, Kolkata - 700019, India, Email abanthro@caluniv.ac.in Received: November 19, 2018 | Published: December 28,
2018

\section{Introduction}

Recognition of human remains is an indispensable element in medico-legal aspects and at the same time one of the major undertaking by the forensic anthropologist is the identification of fragmentary and mutilated remains. The identification of stature of the deceased, and comparisons with the ante-mortem data and age and sex assessment, has been subject matter of many forensic anthropology researches over the time and space. ${ }^{1,2}$ The process of identification is generally imperative in cases of mass disasters, explosions, and assault cases where the body is fragmented and establishing the identity of the victim being the challenge for investigator. ${ }^{3}$ It is here that accurate sexing of the human remains has the potential to primarily narrow down the search to a particular sex thereby giving sense of direction to the ongoing forensic investigation. Although genetic analysis of human population does not support concepts of innate racial differences with respect to innate abilities or characteristics, but human as polytypic and allopatric species demonstrate wide range of morphological, quantitative, polymorphic variations across the word. Being at the crossroads of migration, Indian populations have undergone complex and ancient admixture events over a long period ${ }^{4-6}$ and have been the melting-pot of disparate ancestries originating from different parts of Eurasia and South-East Asia. ${ }^{6}$ Although the date of entry of modern humans into India remains uncertain but it is reasonable to consider by the middle Paleolithic period (50,000-20,000 years before present [ybp]), humans appear to have spread onto many parts of India.? Contemporary ethnic India is a land of enormous genetic, cultural, and linguistic diversity. ${ }^{8,9} \mathrm{~A}$ more recent study exploring Indian genomic 
diversity demonstrated four major ancestral genetic components in mainland India that included four dominant ancestries in populations from mainland India: Ancestral North-Indian (ANI), Ancestral SouthIndian (ASI), Ancestral Tibeto-Burman (ATB) and Ancestral AustroAsiatic (AAA). ${ }^{6}$ Dismembered remains including the terminal parts of the human body such as hands and feet are often found in cases of mass disaster and homicides. Studies have highlighted on the role of hand and foot measurements in establishing the biological profile of individuals in forensic investigations. ${ }^{1-4,10}$ Besides the lengths of the fingers such as 2D:4D ratios have also been used for predicting sex of an individual. Since, the relative lengths of digits are set before birth, ${ }^{11}$ therefore, intra uterine environment that affect the limbs in the critical period of limb formation also related to normal development of limbs which might reflected through the ratio of the parts of the limb dimensions. Apart from finger digit ratios (2D:4D), androgyny score involving bi-acromial and bi-illiac lengths are also found to be the measures, which has significant effect on sexual dimorphism. ${ }^{12}$ On the basis of the literature review on major and contributing publications regarding the stature estimation from hand, other long and finger bones dimensions ${ }^{10-13}$ concerns, it has been found that studies on the indigenous population of Tripura seems to be under represented. In this backdrop, the present study, to best of the knowledge is the first attempt to understand the above mentioned issues on one TibetoBurman speaker endogamous ethnic populations (Chakmas-the migrant group) of North East India (Tripura) and compared with Bengalee population from Eastern India (West Bengal).

\section{Materials and methods}

The participants of the present study were comprised of 100 Chakma females and 100 Bengalee females of 25 to 35 years age ranges. Prior to the study verbal consent were obtained from the participants. The ring finger is the fourth digit (4D) of the human hand and the second most ulnar finger located between the middle finger and the little finger while the index finger is the second digit (2D), located between the thumb and the middle finger and usually the most dexterous and sensitive finger of the hand. ${ }^{14}$ Stature was obtained using standard technique. ${ }^{15}$ Obtained data were doubly checked and analyzed using the SPSS (Version- 16.0). Descriptive and inferential statistics were done in appropriate places and cut off was set as $p=0.05$.

\section{Results and discussion}

Distributions of the anthropometric variables including 2D and Table I Distribution of anthropometric variables of the studied population
4D (Table 1) demonstrated significant $(\mathrm{p}<0.05)$ between the age matched Bengalee and the Chakma females for all the characteristics. Furthermore, the analysis revealed except the bi-acromian length all the anthropometric variables were significantly $(\mathrm{p}<0.05)$ higher in Bengalee females. Examination of estimation of stature through multiplication factors (Table 2) the present study revealed least mean value for the bi-illiac length while, the highest being the mean value for 2D among both the population. However, the comparison between the population the mean multiplication factors for estimation of stature, the length of 2D, 4D and Bi-illac length demonstrated significant $(p<0.05)$ difference between the two population groups belonging two discrete geographical, ecological and linguistic affiliation, indicated differential dimensions in body proportions. So far the forensic issues concern regarding the stature estimation through multiplication factors, the best predictors were Bi-illiac length followed by Biacromian length for both the studied populations. Apart from the analysis of multiplication factors, to understand the relationship of stature and other measures such as bi-acromian, bi-illiac lengths, digit measurements (2D and 4D) correlations have been computed (Table 3). Majority of the measurements demonstrated significant $(p<0.05)$ positive correlation with stature except bi-acromian and biilliac among the Bengalee females and Chakma females respectively. Bengalee females revealed significant $(p<0.05)$ negative correlation between stature and bi-acromian length, while Chakma females showed in contrast the negative correlation between stature and bi-illiac length. It would be apparent from the analysis that, since the Chakmas and Bengalee population are the two discrete ethnic groups and resides in discrete geographical zone, the body structure concerning the bi-acromian and the bi-illiac dimension seems to be variable might be due to adaptability. Furthermore, the comparative analysis of these aspects remains unresolved, since no previous study has been encountered regarding reconstruction of stature by these anthropometric measures for either of the population. So far the coefficient of determination $\left(\mathrm{R}^{2}\right)$ concern, 2D length showed highest $(38.3 \%)$ value to determine the stature for Chakma females, while for Bengalee females highest coefficient of determination (7.1\%) for stature revealed by bi-illiac length. In this circumstance, the study concludes that stature estimation and /or reconstruction from digit (2D and 4D) lengths along with other anthropometric variables (bi-acromian and bi-illiac) lengths should be utilized for specific population group. Therefore, the present study stimulates further studies in different population.

\begin{tabular}{|c|c|c|c|c|c|}
\hline Population & $\begin{array}{l}\text { Stature }(\mathrm{cm}) \\
\text { Mean } \pm \text { SD }\end{array}$ & $\begin{array}{l}\text { 2D }(\mathrm{cm}) \\
\text { Mean士SD }\end{array}$ & $\begin{array}{l}\text { 4D }(\mathrm{cm}) \\
\text { Mean士SD }\end{array}$ & $\begin{array}{l}\text { Bi-Acromial Length }(\mathrm{cm}) \\
\text { Mean } \pm \text { SD }\end{array}$ & $\begin{array}{l}\text { Bi-Illiac } \\
\text { Length (cm) } \\
\text { Mean } \pm S D\end{array}$ \\
\hline Bengalee & $|55.8| \pm 7.48^{*}$ & $7.39 \pm 0.49 *$ & $7.89 \pm 0.5 I^{*}$ & $26.48 \pm 6.28$ & $30.37 \pm 2.91 *$ \\
\hline Chakma & $|5| .2 \mid \pm 4.98$ & $6.22 \pm .0 .41$ & $6.52 \pm .0 .66$ & $29.65 \pm 5.19 *$ & $29.28 \pm 3.64$ \\
\hline
\end{tabular}

$*_{\mathrm{p}}<0.05$

Table 2 Distribution of multiplication Factors for estimation of stature of the studied population

Table 3 Correlation between stature and anthropometric variables of the studied population

\begin{tabular}{lll}
\hline Variables & $\begin{array}{l}\text { Bengalee } \\
(\mathbf{n}=100) \\
\text { Mean } \pm S D\end{array}$ & $\begin{array}{l}\text { Chakma } \\
(\mathbf{n}=100) \\
\text { Mean } \pm S D\end{array}$ \\
\hline Height/2D length & $21.17 \pm 1.67$ & $24.21 \pm 1.26^{*}$ \\
Height/4D length & $19.79 \pm 1.49$ & $23.37 \pm 1.7 I^{*}$ \\
Height/Bi-acromial length & $6.21 \pm 1.53$ & $6.06 \pm 6.47$ \\
Height/Bi-iliac length & $5.14 \pm 0.51$ & $5.62 \pm 1.07^{*}$
\end{tabular}

\begin{tabular}{llllll}
\hline Variable & Predictors & Bengalee & \multicolumn{3}{c}{ Chakma } \\
\cline { 3 - 6 } & & $\mathbf{r}$ & $\mathbf{R}^{2}$ & $\mathbf{r}$ & $\mathbf{R}^{2}$ \\
\hline \multirow{4}{*}{ Height } & 2D & $0.216^{*}$ & 0.046 & $0.619^{*}$ & 0.383 \\
& 4D & $0.258^{*}$ & 0.067 & $0.525^{*}$ & 0.275 \\
& Bi-acromial & $-0.298^{*}$ & 0.089 & $0.237^{*}$ & 0.056 \\
& & $0.266^{*}$ & $0.07 \mathrm{I}$ & -0.126 & 0.016
\end{tabular}

$* p<0.05$

Citation: Ghosh K, Bhattacharya P, Maitra S, et al. Stature estimation from digit length, bi-acromian and bi-illiac length: a study among two populations from eastern and north eastern India. Forensic Res Criminol Int J. 2018;6(6):523-525. DOI: I0.I5406/frcij.20I8.06.00253 


\section{Acknowledgments}

None.

\section{Conflicts of interest}

The corresponding author confirms on behalf of all authors that there have been no involvements that might raise the question of bias in the work reported or in the conclusions, implications, or opinions stated.

\section{References}

1. Ghosh JR, Guin R, Bandyopadhyay AR. Estimation of stature from Foot measurements. Indian. IJRA. 2015;1(1):25-30.

2. Ghosh JR, Bandyopadhyay AR. Estimation of Stature from Index and Ring Finger Lengths. Ind J Phy Anth \& Hum Genet. 2014;33(1):23-29.

3. Cattaneo C. Encyclopedia of forensic sciences. 2 ${ }^{\text {nd }}$ Edition. Academic Press. Elsevier. 2013.

4. Bamshad M, kivisild T, Watkins WS, et al. Genetic evidence on the origins of Indian caste populations. Gen Res. 2001;11:994-1004.

5. Moorjani P, Thangaraj K, Singh L. Genetic evidence for recent population mixture in India. Amer J Hum Genet. 2013;93:422-438.

6. Basu A, Sarkar-Roy N, Majumder PP. Genomic reconstruction of the history of extant populations of India reveals five distinct ancestral components and a complex structure. PNAS. 2016;113:1594-1599.

7. Misra VN. Stone Age in India: An ecological perspective. Man and Env. $1992 ; 14: 17-64$.

8. Karve I. Hindu Society: An interpretation. India. 1961.

9. Majumder PP. People of India: Biological diversity and affinities. Evo Anthrop. 1998;6:100-110.

10. Pal A, De S, Sengupta $\mathrm{P}$, et al. Estimation of stature from hand dimensions in Bengalee population, West Bengal, India. Egypt J Foren Sci. 2016;6(2):90-98.

11. Garn SM, Burdi AR, Babler WJ, et al. Early prenatal attainment of adult metacarpalphalangeal rankings and proportions. Am J Phys Anthrop. 1975;43:327-332.

12. Milne JS. Age Differences. In The Androgyny Score. Brit J Prev Soc Med. 1972;26(4):231-237.

13. Sen J, Kanchan T, Ghosh A, et al. Estimation of Sex From Index and Ring Finger Lengths in An Indigenous Population of Eastern India. $J$ Clin Diagn Res. 2015;9(11):1-5.

14. Fink B, Manning J, Neave N, et al. Second to fourth digit ratio and facial asymmetry. Evol Hum Behav. 2004;25(2):125-132.

15. Lohman TG, Roche AF, Martorell R. Anthropometric Standardization Reference Manual. Chicago: Human kinetics Books. 1988. 